\title{
A PRODUÇÃO DE LEITE NO RIO GRANDE DO SUL: PRODUTIVIDADE, ESPECIALIZAÇÃO E CONCENTRAÇÃO $\left(1990\right.$ - 2009) ${ }^{1}$
}

\author{
Pascoal José Marion Filho ${ }^{2}$ \\ Jones de Oliveira Fagundes ${ }^{3}$ \\ Gabriela Schumacher ${ }^{4}$
}

\begin{abstract}
Resumo: Este artigo avalia a evolução da produtividade, da especialização e da concentração da produção de leite nas microrregiões do Rio Grande do Sul, no período de 1990 a 2009. A produtividade é medida pela razão entre a produção de leite e o número de vacas ordenhadas, a especialização é avaliada pelo Quociente Locacional e a concentração é determinada pelo Gini Locacional, segundo a divisão geográfica de microrregiões do IBGE. Os resultados da pesquisa mostram que crescem a produtividade, a especialização e a concentração na produção de leite, com destaque para as microrregiões de Três Passos, com QL igual a 2,33 em 2008, e de Passo Fundo, com produtividade de 4.197 litros/vaca em 2009. O Gini Locacional também apresentou um crescimento expressivo no período $1990-2009$ (56,25\%), passando de 0,32 para 0,50 .
\end{abstract}

Palavras-chave: Leite; Produtividade; Quociente Locacional; Gini Locacional.

Abstract: This article evaluates the evolution of productivity, specialization and concentration of milk production in microregions of Rio Grande do Sul in the period 1990 to 2009. Productivity is measured by the ratio between milk production and the number of cows milked, the specialization is calculated from the location quotient (QL) and concentration is determined by the location Gini (GL), according to the geographical division of microregions of IBGE. The survey results showed that increases productivity, specialization and concentration in milk production, with emphasis on microregions of Três Passos, with QL equal to 2,33 in 2008, and Passo Fundo, with productivity of 4.197 liters/cow in 2009. The location Gini also showed a significant growth in the period $1990-2009(56.25 \%)$, went from 0.32 to 0.50 .

Keywords: Milk; Productivity; Location Quotient; Location Gini.

Recebido em: 29/06/2011. Aceito em: 18/10/2011.

Professor Associado da Universidade Federal de Santa Maria (UFSM). Email: pascoaljmarion@yahoo.com.br.

3 Graduando em Ciências Econômicas pela Universidade Federal de Santa Maria

-UFSM. Email: jonesof@yahoo.com.br.

4 Mestranda em Administração pela Universidade Federal de Santa Maria - UFSM.

Email: gabi.schumacher@hotmail.com. 


\section{Introdução}

No final da década de 1980 e início dos anos noventa, o novo ambiente competitivo internacional, resultante da adoção de políticas econômicas mais liberais, induziu profundas mudanças na economia brasileira. O setor de laticínios teve também a desregulamentação do mercado, que alterou as regras para os produtores e o restante do sistema.

A desregulamentação serviu de incentivo à entrada de novas empresas no setor, já que permitiu aos produtores atuar com maior grau de liberdade, pois o tabelamento de preços do leite e de seus derivados agia como um desestímulo à criação de produtos de maior valor agregado, visto que o preço era determinado pelo governo. Assim, com a liberalização dos preços, as agroindústrias incentivaram e passaram a fazer pagamentos diferenciados pela matéria-prima, observando as características do produto (CARVALHO, 2002).

Segundo Carvalho (2002, p.2):

A abertura da economia brasileira, seja a facilitação da entrada de produtos industrializados, seja o aumento do fluxo de investimento direto externo, contingenciou uma mudança de postura das empresas residentes no país, que após um período de acomodação tiveram que adaptar-se as novas condições de mercado. A busca de vantagens competitivas fez com que as empresas buscassem um aumento de escala, possibilitando assim a realização de investimentos de maior monta. Esse processo levou a constituição de grandes firmas industriais.

Guimarães (2008) comenta que a determinação governamental de abrir o mercado levou o Brasil a despertar para o tema competitividade. Vivendo anteriormente num aspecto competitivo basicamente restrito ao território 
nacional, as cooperativas brasileiras de leite, de capital nacional, se viram obrigadas a se reestruturar sob a ameaça de desaparecerem. A indústria de laticínios se expandiu após a década de 1990, apresentando empresas gigantes, concentradoras e com a capacidade de atender a todo o mercado nacional e até mesmo exportar, fato até então raro no setor.

A formação do Mercosul também contribuiu para o surgimento de mudanças importantes no setor, uma vez que trouxe a extinção de tarifas diferenciadas para os países, e a implantação do Real em 1994 gerou uma forte valorização da moeda brasileira. Com isso, o país passou a importar leite, especialmente dos países vizinhos, Uruguai e Argentina. Em 1999, ocorreu uma forte desvalorização da moeda brasileira e o produto gerado internamente voltou a ser competitivo. Diante da nova situação, Carvalho (2002) afirma que o produtor de matéria-prima teve que realizar investimentos para aumentar a produtividade e/ou a produção em face das exigências da indústria, sob pena de ser excluído da cadeia produtiva.

As afirmações de Carvalho (2002) e de Guimarães (2008) sobre mudanças no sistema agroindustrial do leite (SAG) servem para todos os sistemas dispersos no território nacional. O SAG do Rio Grande do Sul, como apontam Silveira e Pedrazzi (2009), também não ficou imune ao processo e isto abre uma importante agenda para estudos regulares e sistemáticos, já que a importância social deste sistema não pode ser ignorada.

No Rio Grande do Sul, as agroindústrias processadoras de leite fluido reestruturaram-se e focaram a produção para a venda do leite longa vida, adaptando-se ao novo cenário brasileiro. Finamore e Maroso (2004) constataram que no período de 1990 a 2003 houve aumento na produtividade e na produção de leite no Estado, decorrente do melhoramento genético, da nutrição animal e de avanços tecnológicos, com estabilização do rebanho de vacas ordenhadas.

Em 2005, 74.118 famílias gaúchas tinham o leite como sua base de renda mensal, sendo o Rio Grande do Sul o terceiro maior produtor do Brasil, 
com sete milhões de litros por dia. A indústria gaúcha tem 232 empresas, exporta leite para 25 países e gera 686.904 empregos diretos e indiretos (DIÁRIO POPULAR, 2006 apud LATICINIO.NET, 2009).

Frente ao exposto, verifica-se que a produção de leite é importante no Estado e que ocorreram mudanças relevantes no ambiente econômico interno e externo, o que alterou o padrão de concorrência, o processo de produção e a distribuição espacial. Por isso, a pesquisa tem como objetivo avaliar a evolução da produtividade, da especialização e da concentração da produção de leite nas microrregiões do Rio Grande do Sul, no período de 1990 a 2009.

O artigo está organizado em quatro seções, sendo essa introdução a primeira delas. Na segunda seção, é apresentada a metodologia da pesquisa e na terceira seção, a análise da produtividade, da concentração e da especialização na produção de leite no Rio Grande do Sul. As conclusões da pesquisa estão na quarta seção do trabalho.

\section{Metodologia}

A produtividade na produção de leite é medida pela razão entre a produção total de leite no município, microrregião ou Estado e o número de vacas ordenhadas. A especialização e a concentração na produção de leite nas microrregiões do Rio Grande do Sul são avaliadas, respectivamente, pelo Quociente Locacional (QL) e pelo Gini Locacional (GL). Segundo Suzigan et al. (2003, p. 44), os "[...] indicadores permitem verificar a distribuição espacial, identificar especializações regionais e mapear movimentos de deslocamento regional das atividades econômicas, sejam decorrentes de processos de concentração ou de desconcentração econômica".

Os trabalhos de economia regional de Isard (1973) e Haddad (1989) servem de referência para a utilização do QL. O GL é igualmente conhecido e vem sendo utilizado junto com o QL em análises sobre 
concentração industrial (SUZIGAN et al., 2003), o que não impede sua aplicação em outros setores.

O Quociente Locacional é uma medida de especialização regional relativa, um instrumento que tem por finalidade comparar determinadas atividades particulares a partir de um agregado básico (no artigo, a proporção entre o valor da produção de leite e o valor adicionado na agropecuária). Segundo Isard (1973), o pesquisador pode utilizar qualquer base que acredite ser apropriada para a pesquisa em questão. A fórmula do QL adotada na pesquisa é a seguinte:

$\mathrm{QL}=\frac{(\mathrm{VPLj} / \mathrm{VAAj})}{(\text { VPLRS / VAARS })}$

Sendo:

VPLj = valor da produção de leite na microrregião j;

$\mathrm{VAA} j=$ valor adicionado na agropecuária da microrregião $\mathrm{j}$;

VPLRS = valor da produção de leite no RS; e

VAARS $=$ valor adicionado na agropecuária do RS.

Para o Quociente Locacional, foi utilizada uma variável de controle, QL $>2$, visando a destacar os resultados mais importantes. Portanto, na análise, são apresentados apenas os quocientes das microrregiões que atingiram uma especialização igual ou superior a duas vezes a calculada para o Estado em um dos anos pesquisados (1990, 1996, 2000, 2005 e 2008).

Entretanto, como afirma Puga (2003, p. 11), o QL tem que ser visto com cautela, pois tende a superestimar a especialização em pequenas localidades e a subestimá-la em grandes, nas quais a diversidade de atividades é maior, especialmente quando se utiliza o número de 
trabalhadores como indicador. Segundo o autor: "uma microrregião com reduzido contingente de trabalhadores, mas com especialização da produção em determinando bem ou serviço, tende a apresentar elevado QL sem ter, no entanto, uma concentração mínima de empresas e trabalhadores".

Suzigan et al. (2003, p. 46) também enfatizam a limitação do indicador quando citam que: "uma região pouco desenvolvida industrialmente poderá apresentar um elevado índice de especialização simplesmente pela presença de uma unidade produtiva, mesmo que de dimensões modestas".

No entanto, como a relação utilizada no artigo não está baseada no número de trabalhadores e não foca um setor industrial em específico, a limitação fica minimizada, até porque a agropecuária é importante economicamente em todas as 35 microrregiões do Estado do Rio Grande do Sul.

O Gini Locacional (GL) mostra a concentração espacial de uma atividade, ou seja, a distribuição homogênea da mesma na área-base. O GL pode ser obtido pelas seguintes fórmulas:

$$
\begin{aligned}
& S=\sum_{k=1}^{n}\left(Y_{k}-Y_{k-1}\right)\left(\frac{x_{k+} x_{k-1}}{2}\right) \\
& \alpha=0,5-S \\
& G L=\frac{\alpha}{0,5}=2 \alpha
\end{aligned}
$$

Sendo:

$Y=$ Proporção acumulada da razão entre o valor da produção de leite na microrregião $j$ (VPLj) e o valor da produção de leite no Rio Grande do Sul (VPLRS), após a organização das razões (VPLj/VPLRS) em ordem decrescente; e

$X=$ Proporção acumulada da razão entre uma microrregião e o número total das mesmas no Estado. 


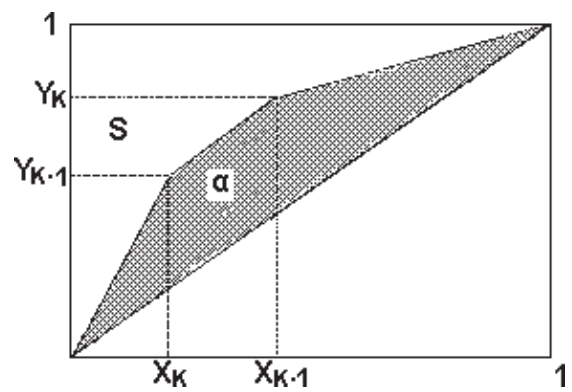

Figura 1 - Área de concentração

Fonte: Elaborada pelos autores.

A Figura 1 mostra no eixo das ordenadas a proporção acumulada de $\mathrm{Y}$ e no eixo das abscissas a proporção acumulada de X. Como os dados trabalhados são decimais, o acumulado máximo nas duas direções é 1 (um). Assim sendo, a área total da figura também é 1 (um). A reta que parte da origem e segue até o ponto $\mathrm{A}$, formando um ângulo de $45^{\circ}$, é chamada de "linha de perfeita igualdade", pois as variáveis expostas sobre ela têm o mesmo valor. A curva de localização é formada pelos pontos das proporções acumuladas das variáveis $\mathrm{X}$ e $\mathrm{Y}$.

Verifica-se que a forma de apresentação do Gini Locacional é idêntica ao do Gini tradicional, diferenciando-se apenas na disposição da curva de localização acima da linha de $45^{\circ}$, já que, a exemplo de Suzigan et al. (2003) e Puga (2003), os resultados das razões são ordenados em ordem decrescente.

O Gini Locacional (GL) é igual ao dobro da área entre a curva de localização e a linha de $45^{\circ}(\alpha)$, uma vez que o $\alpha$ é calculado para $1 / 2$ da área total (igual a 1). Assim, os limites para o GL vão de 0 (zero) a 1 (um) $(0<\mathrm{GL}<1)$. Quanto mais próximo da unidade o GL, maior a concentração geográfica da produção de leite no Estado. Por outro lado, quanto mais próximo de zero, maior a distribuição espacial da atividade. 
Sobre a utilização do GL, assim como do índice de Gini, existem restrições na avaliação da concentração industrial quando o número de informações utilizadas é reduzido, menor que 10 (LABINI, 1986), o que não é o caso nessa pesquisa, uma vez que o Estado tem 35 microrregiões.

Os dados utilizados no estudo são do IBGE (Pesquisa Pecuária Municipal) e da Fundação de Economia e Estatística do Rio Grande do Sul (FEE).

\section{Análise dos resultados}

A análise da produção de leite nas microrregiões do Rio Grande do Sul está dividida em três partes. A primeira identifica as regiões com maior produção e produtividade do Brasil e do Estado, a segunda identifica as regiões do Rio Grande do Sul com maior especialização e a terceira avalia a evolução da concentração nas microrregiões.

\subsection{A produtividade e a produção de leite no Rio Grande do Sul}

Segundo dados do IBGE (2011), a produção de leite no Brasil vem crescendo continuamente e, no período de 1990 a 2009, aumentou $100,94 \%$. As regiões Sudeste e Sul do país continuam sendo as mais importantes na geração do produto e, juntas, responderam por, aproximadamente, dois terços da produção nacional de leite de 2009 (66,64\%). Entretanto, no período de 1990 a 2009, a expansão da produção no Sul foi superior à ocorrida no Sudeste, $175,19 \%$ contra $50,50 \%$, respectivamente. Esse desempenho diferenciado das regiões fez com que o Sul aumentasse a sua participação no total nacional do produto, de 22,52\% em 1990 para 30,84\% em 2009, e na Sudeste, caísse de 47,80\% para $35,80 \%$. 
Tabela 1 - A participação e a evolução da produção de leite nos estados da Região Sul do Brasil em 1990 e 2009

\begin{tabular}{lrrr}
\hline Região & $\begin{array}{c}\text { Evolução da produção } \\
(\%)\end{array}$ & Participação 1990 (\%) & Participação 2009 (\%) \\
\hline Região Sul & 175,19 & 100,00 & 100,00 \\
Rio Grande do Sul & 134,20 & 44,50 & 37,88 \\
Santa Catarina & 244,06 & 19,94 & 24,93 \\
Paraná & 187,86 & 35,56 & 37,20 \\
\hline
\end{tabular}

Fonte: Elaborada pelos autores com dados do IBGE (SIDRA).

Na Região Sul, o desempenho dos estados na produção de leite foi diferente nos anos de 1990 e 2009, sendo o de Santa Catarina o maior (244,06\%), seguido por Paraná (187,86\%) e Rio Grande do Sul (134,20\%). Mesmo com um crescimento superior na produção, Santa Catarina ainda teve a menor participação na produção da região em 2009 (24,93\%), com Paraná em segundo $(37,20 \%)$ e o Rio Grande do Sul em primeiro (37,88\%). No entanto, em relação a 1990, o Rio Grande do Sul perdeu participação na produção de leite na Região Sul (Tabela 1).

Quanto à produtividade por vaca ordenhada em 2009, os estados do Sul têm as três maiores do Brasil, sendo a de Santa Catariana a maior delas (2.397 litros), seguida pelo Rio Grande do Sul (2.334 litros) e Paraná (2.242 litros). No mesmo ano, a produtividade no País foi de 1.297 litros. De 1990 para 2009, a produção de leite por vaca ordenhada aumentou $88,68 \%$ no Rio Grande do Sul, tendo passado de 1.237 litros para 2.334 litros (Tabela 2). 
Tabela 2 - Evolução da produtividade de leite no Brasil e nos estados da Região Sul (1990/2009)

\begin{tabular}{lrrr}
\hline Região/Estado & $\begin{array}{c}\text { Produtividade em } \\
1990 \text { (litros) }\end{array}$ & $\begin{array}{c}\text { Produtividade em 2009 } \\
\text { (litros) }\end{array}$ & $\begin{array}{c}\text { Evolução da } \\
\text { Produtividade (\%) }\end{array}$ \\
\hline Brasil & 759 & 1297 & 70,88 \\
Região Sul & 1154 & 2314 & 100,52 \\
Rio Grande do Sul & 1237 & 2334 & 88,68 \\
Santa Catarina & 1155 & 2397 & 107,53 \\
Paraná & 1064 & 2242 & 110,71 \\
\hline
\end{tabular}

Fonte: Elaborada pelos autores com dados do IBGE (SIDRA).

Mesmo tendo uma das maiores produtividades do Brasil em 2009, atrás apenas de Santa Catarina, a do Rio Grande do Sul continua distante das obtidas em 2008 por países altamente especializados, como Japão (9.260 litros/vaca), Estados Unidos (9.250 litros) e Canadá (8.400 litros), segundo USDA (2010). Na mesma publicação e no mesmo ano, o Brasil aparece com uma produtividade de 1.670 litros/vaca e a Argentina com 4.660 litros.

Em termos de volume produzido, as dez microrregiões do Rio Grande do Sul com maior produção de leite em 2009 são: Passo Fundo, Três Passos, Lajeado-Estrela, Santa Rosa, Guaporé, Erechim, Frederico Westphalen, Ijuí, Carazinho e Cruz Alta (Tabela 3). Estas regiões produziram juntas $63,93 \%$ do leite gerado no Estado e fazem parte das mesorregiões Noroeste e Nordeste, exceto a microrregião de Lajeado - Estrela, que faz parte da Centro Oriental.

Tabela 3 - Microrregiões do Rio Grande do Sul que mais produziram leite em 2009

\begin{tabular}{lclc}
\hline Microrregião & Mil litros & Microrregião & Mil litros \\
\hline Passo Fundo & 425.088 & Erechim & 194.142 \\
Três Passos & 234.644 & Frederico Westphalen & 187.071 \\
Lajeado-Estrela & 234.312 & Ijuí & 181.450 \\
Santa Rosa & 209.894 & Carazinho & 163.591 \\
Guaporé & 194.745 & Cruz Alta & 148.879 \\
\hline
\end{tabular}

Fonte: Elaborada pelos autores com dados do IBGE (SIDRA). 
As microrregiões de Passo Fundo, Não-Me-Toque, Guaporé e Cruz Alta ultrapassaram a produção de três mil litros de leite por vaca ordenhada em 2009 e apresentaram um aumento importante de produtividade: Passo Fundo (4197 litros; 214,28\% de crescimento), Não-Me-Toque (4.022 litros; 128,22\%), Guaporé (3.408 litros; 148,83\%) e Cruz Alta (3.236 litros; 136,93\%) (Tabela 4).

Tabela 4 - As dez microrregiões do Rio Grande do Sul com maior produtividade de leite em 1990 e 2009

\begin{tabular}{lclc}
\hline $\begin{array}{l}\text { Ano 1990 } \\
\text { Microrregião }\end{array}$ & Litros/Vaca & Ano 2009 & Microrregião \\
\hline Não-Me-Toque & 1762 & Passo Fundo & 4197 \\
Lajeado-Estrela & 1622 & Não-Me-Toque & 4022 \\
Santa Rosa & 1526 & Guaporé & 3408 \\
Ijuí & 1456 & Cruz Alta & 3236 \\
Caxias do Sul & 1417 & Sananduva & 2954 \\
Erechim & 1415 & Lajeado-Estrela & 2829 \\
Três Passos & 1378 & Santa Rosa & 2812 \\
Guaporé & 1370 & Três Passos & 2781 \\
Cruz Alta & 1366 & Ijuí & 2780 \\
Cerro Largo & 1359 & Soledade & 2659 \\
\hline
\end{tabular}

Fonte: Elaborada pelos autores a partir de dados do IBGE (SIDRA).

Portanto, a microrregião de Passo Fundo detém o maior volume produzido e a maior produtividade por vaca ordenhada em 2009, mesmo não figurando entre as dez de maior produtividade em 1990. Além disso, tem cinco municípios entre os vinte de maior produção do Estado, sendo Marau o maior de todos.

Os demais municípios são: Casca, Passo Fundo, Vila Maria e Pontão. Também chama atenção a taxa de crescimento da produção de leite nestes municípios, pois, nos últimos sete anos (2002/2009), Marau aumentou a produção em 73,34\%, Casca em 154,96\%, Passo Fundo em $75,16 \%$, Vila Maria em 110,66\% e Pontão em 161,57\%. A pesquisa também revelou que em 17 das 35 microrregiões o número de vacas ordenhadas em 2009 é menor do que o existente em 1990, indicando uma maior concentração e especialização na atividade leiteira. 
3.2. A especialização na produção de leite do Rio Grande do Sul

A crescente produção de leite destes últimos anos no Rio Grande do Sul vem ocorrendo de forma desigual, mudando o mapa regional na geração do produto. A microrregião de Três Passos tornou-se a mais especializada em 2008 e vem acompanhada, em ordem decrescente de importância, pelas regiões de Passo Fundo, Guaporé, Santa Rosa, Cerro Largo. Estas regiões são de especialização recente, já que atingiram o coeficiente 2 nos anos de 2000 e/ou 2005, e Guaporé apenas em 2008 (Tabela 5). Por outro lado, Gramado-Canela, Lajeado-Estrela e Vacaria se tornaram não-especializadas.

Tabela 5 - Quociente Locacional das principais microrregiões produtoras de leite do Rio Grande do Sul

\begin{tabular}{lrrrrr}
\hline Microrregião & 1990 & 1996 & 2000 & 2005 & 2008 \\
\hline Três Passos & 0,92 & 1,59 & 1,84 & 2,21 & 2,33 \\
Passo Fundo & 0,91 & 1,01 & 1,47 & 3,07 & 2,29 \\
Guaporé & 1,06 & 1,10 & 1,17 & 1,89 & 2,27 \\
Santa Rosa & 1,48 & 1,73 & 2,61 & 2,71 & 2,20 \\
Cerro Largo & 1,20 & 1,95 & 2,25 & 2,03 & 2,10 \\
Não-Me-Toque & 0,81 & 1,89 & 2,06 & 2,40 & 1,38 \\
Ijuí & 1,22 & 1,67 & 1,69 & 2,78 & 1,48 \\
Sananduva & 1,02 & 0,91 & 1,10 & 2,21 & 1,65 \\
Gramado-Canela & 2,15 & 2,18 & 1,69 & 1,47 & 1,62 \\
Lajeado-Estrela & 2,41 & 1,86 & 2,35 & 1,53 & 1,99 \\
Vacaria & 2,77 & 0,86 & 0,61 & 0,48 & 0,36 \\
\hline
\end{tabular}

Fonte: Elaborada pelos autores a partir de dados do IBGE (SIDRA) e da FEE (FEEDADOS). 
As microrregiões especializadas na produção de leite em 2008 são próximas entre si e se localizam na mesorregião Noroeste do Rio Grande do Sul, com exceção de Guaporé, que fica na mesorregião Nordeste (Figura 2). Embora a microrregião de Três Passos tenha o maior QL do Estado, Passo Fundo continua sendo a região mais importante, pois produziu 425.088 mil litros de leite em 2009 e teve uma expansão da atividade no período 1990/2009 igual a 592,46\%. Além disso, teve a maior produtividade em 2009 e seu maior incremento no período, respectivamente, 4.197 litros e $214,28 \%$.

Estes dados mostram que a região é especializada e que a atividade vem se expandindo, corroborando os resultados obtidos pelo QL. No entanto, cabe salientar que o Quociente Locacional de 2008 pode não mostrar plenamente essa expansão, uma vez que uma forte seca atingiu o Estado nos anos de 2007/2008. Conforme Nedel et al. (2010), a seca foi provocada pelo fenômeno La Niña e teve intensidade forte na região, o que prejudicou a produção agropecuária, inclusive a do leite. 

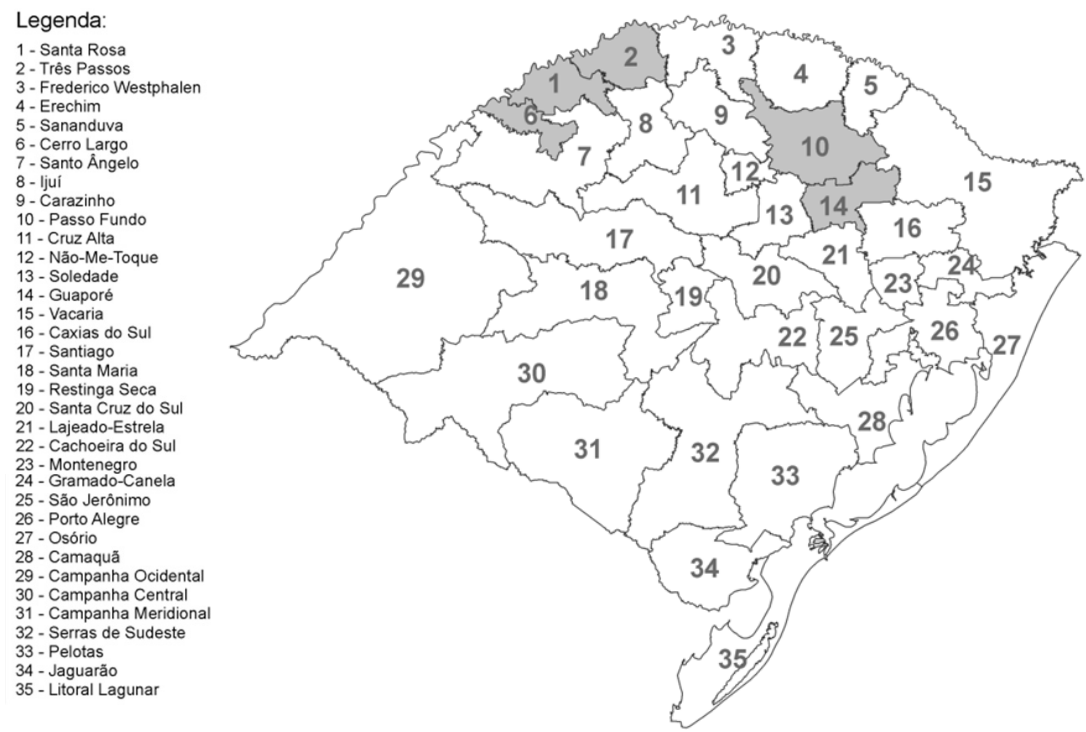

Figura 2 - Mapa do Rio Grande do Sul com as microrregiões especializadas na produção de leite de 2008

Fonte: Elaborada pelos autores a partir de IBGE (2009).

Entre as microrregiões de maior redução na produção de leite do Estado, estão Osório, Cachoeira do Sul e Camaquã, todas com mais de 45\%. E entre as microrregiões de maior expansão, estão Carazinho, Passo Fundo, Soledade, Não-Me-Toque e Guaporé, todas com mais de 300\% (Tabela $6)$. 
Tabela 6 - As dez microrregiões do RS que tiveram maior expansão ou redução da produção de leite de 1990 para 2009

\begin{tabular}{lrlr}
\hline Microrregião & $\%$ Microrregião & $\%$ \\
\hline Carazinho & 611,42 & Osório & $-66,86$ \\
Passo Fundo & 592,46 Cachoeira do Sul & $-47,98$ \\
Soledade & 348,35 Camaquã & $-46,94$ \\
Não-Me-Toque & 313,63 São Jerônimo & $-31,85$ \\
Guaporé & 304,51 Santa Cruz do Sul & $-28,17$ \\
Sananduva & 297,11 Serra do Sudeste & $-21,28$ \\
Três Passos & 288,21 Restinga Seca & $-17,01$ \\
Ijuí & 232,50 Montenegro & $-16,70$ \\
Santa Rosa & 218,97 Vacaria & $-13,95$ \\
Santiago & 218,61 Santa Maria & $-11,49$ \\
\hline
\end{tabular}

Fonte: Elaborada pelos autores com dados do IBGE (SIDRA).

Portanto, verifica-se que algumas regiões apresentam uma importante expansão na produção de leite e outras uma forte contração, o que também contribui para explicar a especialização na produção verificada no Rio Grande do Sul.

\subsection{A concentração na produção de leite do Rio Grande do Sul}

No subitem 3.2, constatou-se que a evolução da produção de leite vem ocorrendo de modo desigual no Estado, com expansão em algumas regiões e retração em outras. Pelo Gini Locacional, é possível verificar que a dinâmica apresentada na geração do produto está contribuindo também para ampliar a concentração da produção (Gráfico 1). 


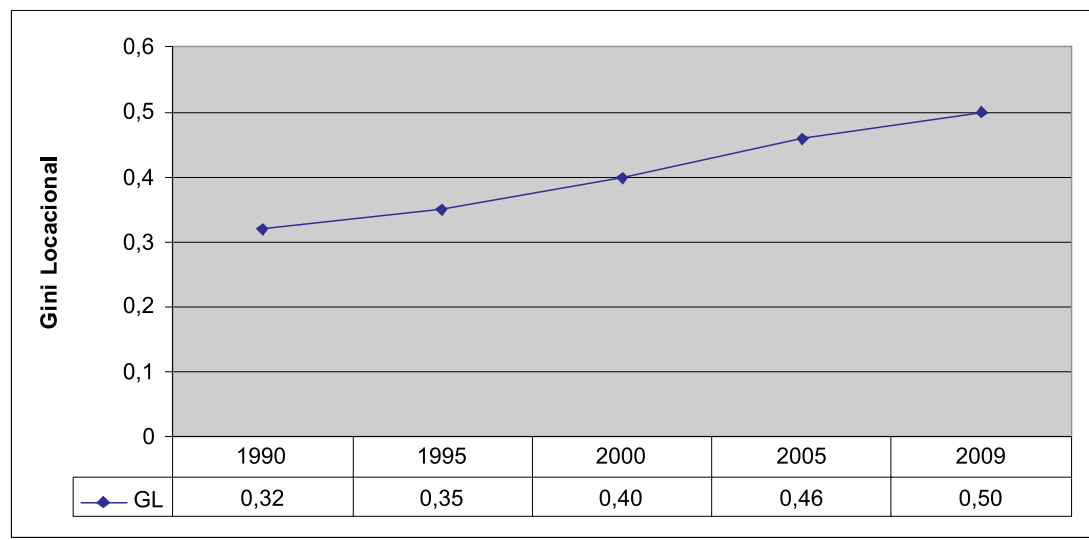

Gráfico 1 - Evolução da concentração na produção de leite do RS Fonte: Elaborado pelos autores com dados do IBGE (SIDRA).

Os índices calculados mostram o crescimento na concentração da produção de leite do Rio Grande do Sul e que, tomando 2009 em relação a 1990 , ela aumentou $56,25 \%$. Logo, pode-se afirmar com a pesquisa que a concentração vem aumentando não apenas pela maior expansão da atividade em algumas regiões, mas porque está caindo a produção de leite nas regiões localizadas mais ao sul do Estado e nas mesorregiões Metropolitana de Porto Alegre e Centro.

\section{Conclusões}

A pesquisa teve como objetivo avaliar a evolução da produtividade, da especialização e da concentração da produção de leite nas microrregiões do Rio Grande do Sul no período de 1990 a 2009. Os resultados mostram que crescem a produtividade, a especialização e a concentração na produção de leite do Estado, sendo a região noroeste a mais dinâmica e, dentro dela, a de Três Passos, a mais especializada.

De 1990 para 2009, a produtividade no Estado aumentou 88,68\%, menos do que nos demais estados da Região Sul, passando de 1237 para 2334 litros. A microrregião de Passo Fundo teve a maior produtividade do Rio 
Grande do Sul em 2009 (4197 litros) e a maior produção (425.088 mil litros).

Das trinta e cinco microrregiões, cinco tiveram Quociente Locacional igual ou superior a 2 (dois) em 2009: Três Passos (2,33), Passo Fundo $(2,29)$, Guaporé $(2,27)$, Santa Rosa $(2,20)$ e Cerro Largo $(2,10)$. Portanto, estas regiões têm uma relação entre o valor da produção de leite e o valor da produção agropecuária superior a duas vezes à do Estado, caracterizando-as na pesquisa como especializadas.

Entre 1990 e 2009, a produção de leite no Rio Grande do Sul cresceu $134,20 \%$. Entretanto, três microrregiões tiveram uma expansão bem superior à apresentada pelo Estado: Carazinho (611,2\%), Passo Fundo $(592,46 \%)$ e Soledade $(304,51 \%)$. No outro extremo, três apresentaram forte contração na produção: Osório (-66,86\%), Cachoeira do Sul ($47,98 \%$ ) e Camaquã (-46,94\%). Diante do quadro apresentado, pode-se concluir que a desigualdade na produção está se acentuando.

O Gini Locacional (GL) confirma o aumento da concentração (desigualdade) na produção de leite, pois em 1990 o GL foi igual a 0,32 e cresceu continuamente até chegar em 2009 com 0,50, um aumento de $56,25 \%$.

Embora os resultados da pesquisa mostrem, com certa segurança, que estão crescendo a produtividade, a especialização regional e a concentração da produção de leite, deve-se ter cautela, já que são medidas relativas, porquanto o crescimento delas pode vir até mesmo da redução dos preços dos demais produtos ou do abandono de atividades agropecuárias. Logo, com base nos dados da pesquisa, não é possível afirmar se esse movimento é bom ou ruim, mas tão somente que está ocorrendo no Rio Grande do Sul. 


\section{Referências}

CARVALHO, V. R. F. Indústria de laticínios no Rio Grande do Sul: um panorama após o movimento de fusões e aquisições. $1^{\circ}$ Encontro de Economia Gaúcha, 2002. Disponível em: www.fee.tche.br/sitefee/ download/eeg/1/mesa_10_carvalho.pdf. Acesso em: 03 jun. 2009.

FEE - Fundação de Economia e Estatística Siegfried Emanuel Heuser. Disponível em: http://www.fee.rs.gov.br/feedados/consulta/ sel_modulo_pesquisa.asp. Acesso em: 24 mar. 2011.

FINAMORE, E. B.; MAROSO, M. T. D. A dinâmica da cadeia de lácteos gaúcha no período de 1990 a 2003: um enfoque no Corede Nordeste. Disponível em: http://www.fee.tche.br/3eeg/Artigos/ m01t01.pdf. Acesso em: ago. 2009.

GUIMARÃES, J. N. Transnacionalização das Cooperativas de Laticínios: Estudo de caso das Cooperativas Brasileiras em comparativo com as Cooperativas Internacionais, visando à Competitividade Globalizada. Revista de Administração da Unimep. v.6, n.1, jan./abr., 2008.

HADDAD, Paulo Ricardo. Medidas de localização e de especialização. In: HADDAD, Paulo Ricardo; et al. (Orgs.). Economia regional: teorias e métodos de análise. Fortaleza: BNB-ETENE, 1989.

IBGE - Instituto Brasileiro de Geografia e Estatística. Disponível em: http://www.sidra.ibge.gov.br. Acesso em: 17 abr. 2011.

ISARD, Walter. Métodos de análisis regional: una introducción a la ciencia regional. 2. ed. Barcelona: Arial, 1973.

LABINI, P. S. Oligopólio e Progresso Técnico. 2. ed. São Paulo: Nova Cultural, 1986.

LATICINIO.NET. Disponível em: http://www.laticinio.net/ noticias.asp?cod=3943. Acesso em: set. 2009. 
NEDEL, A. S.; SAUSEN, T. M.; SAITO, S. M. Zoneamento dos desastres naturais ocorridos no estado do Rio Grande do Sul no período 2003 - 2009. Santa Maria, 2010. Parte I. Disponível em: http:// www.cbmet2010.com/anais/artigos/20_95661.pdf. Acesso em: 31 mai. 2011.

PUGA, F. P. Alternativas de apoio a MPMES localizadas em arranjos produtivos locais. Rio de Janeiro: BNDES, Textos para Discussão 99, jun. 2003.

SILVEIRA, Vicente Celestino Pires.; PEDRAZZI, Paulo Ramon. As transformações na cadeia produtiva do Leite: impactos no Rio Grande do Sul e em Santa Maria. Santa Maria, 2002. Disponível em: http://www.ufsm.br/cieper/mainfiles/Resumo CPILeite2.doc. Acesso em: out. 2009 .

SUZIGAN, W; FURTADO, J.; GARCIA, R.; SAMPAIO, S. E. K. Coeficientes de Gini locacionais - GL: aplicação à indústria de calçados do Estado de São Paulo. Nova Economia, Belo Horizonte, p. 39-60, jul.- dez. 2003.

USDA. United States Department of Agriculture. World Markets and trade. Disponível em: http://www.fas.usda.gov/dlp/circular/2009/ 122909dairyfull.pdf. Acesso em: 30 nov. 2010. 
REVISTA DE ECONOMIA E AGRONEGÓCIO, VOL.9, $N^{\circ} 2$ 